\title{
Estimation of land-use changes on Kitulo Plateau, Tanzania, using satellite imagery
}

\author{
Jon C. Lovett and Erik Prins
}

The Kitulo Plateau of southern Tanzania is a lava plateau covering $273 \mathrm{sq} \mathrm{km}$ at an altitude of over $2500 \mathrm{~m}$. The vegetation is predominately grassland with more than 350 taxa of wascular plants, of which nearly 5 per cent are of restricted distribution. Although the plateau is extensive, much of it is now cultivated. Digital analysis of satellite images showed that at least 24 per cent of the plateau was bare soil, modified grassland or cultivation between 1973 and 1989. The botanical importance of the plateau and increase in cultivation make a strong case for the establishment of a nature reserve to protect its rare and threatened plants.

Tanzania has a rich flora, with around 10,000 vascular plant species, of which 10-15 per cent are country endemics with many more nearendemics (Brenan, 1978). The reason for this richness is that several phytogeographical zones meet in Tanzania (White, 1983), and there is a wide variety of vegetation types, ranging through a large range of altitudes and climates. In recent years vegetation-orientated conservation efforts in Tanzania have focused on the Eastern Arc and coastal forests (Lovett, 1992; Sheil, 1992; Rodgers, 1993). While these areas are important, there are a number of other vegetation types in Tanzania that have been identified as being worthy of protection (Polhill, 1968, 1988). For example many species of restricted distribution occur in heaths and grasslands above moist forest at altitudes where frost becomes a regular feature. At the highest altitudes, such as on Kilimanjaro in northern Tanzania, there is a unique flora, with giant Lobelia and Senecio (Hedberg, 1957) and many taxa of temperate affinities, as opposed to the tropical nature of the forests below (Lovett, 1993).

In southern Tanzania, the Kitulo Plateau is an area of high-altitude grassland that has long been recognized as botanically important (Cribb and Leedal, 1982; Lovett, 1990; Lovett et al., in press). Formerly known as the Elton Plateau, after James Elton who crossed the plateau in October 1877 shortly before his death near Dodoma (Elton and Cotteril, 1879), the Kitulo is an area of outstanding scenery with beautiful plants. The following notes made by the geographer and engineer Clement Gillman, who travelled extensively in the then Tanganyika Territory (Hoyle, 1986), describe the grasslands well.

'The mountain steppe, especially framed by some rocky heights as on the Mahanga Pass and when seen in flower, reminds one very much of the meadows of the Fore Alps, and the swampy little valley of a lateral stream, the herds of cattle, the long rectangular huts of the natives perched on a slope here and there, and looking exactly like Alpine cow-huts, increase the similarity. On a short walk of an hour one morning we picked not less than eighty-eight different kinds of flowering plants, all in blossom; purple and yellow, ... and beautiful large irises, gladiolas, and orchids delighted our eye' (Gillman, 1927).

At first sight it would appear that high-altitude heaths and grasslands are well protected in Africa and not in need of conservation action. Africa's highest mountain, Kilimanjaro, is covered by a national park above the tree line. Forest reserves cover Mt Mbeya, Mt Hanang, the Lukwangule plateau of the Uluguru Mountains, Selebu Ridge of the northern Udzungwa Mountains, and $\mathrm{Mt}$ 


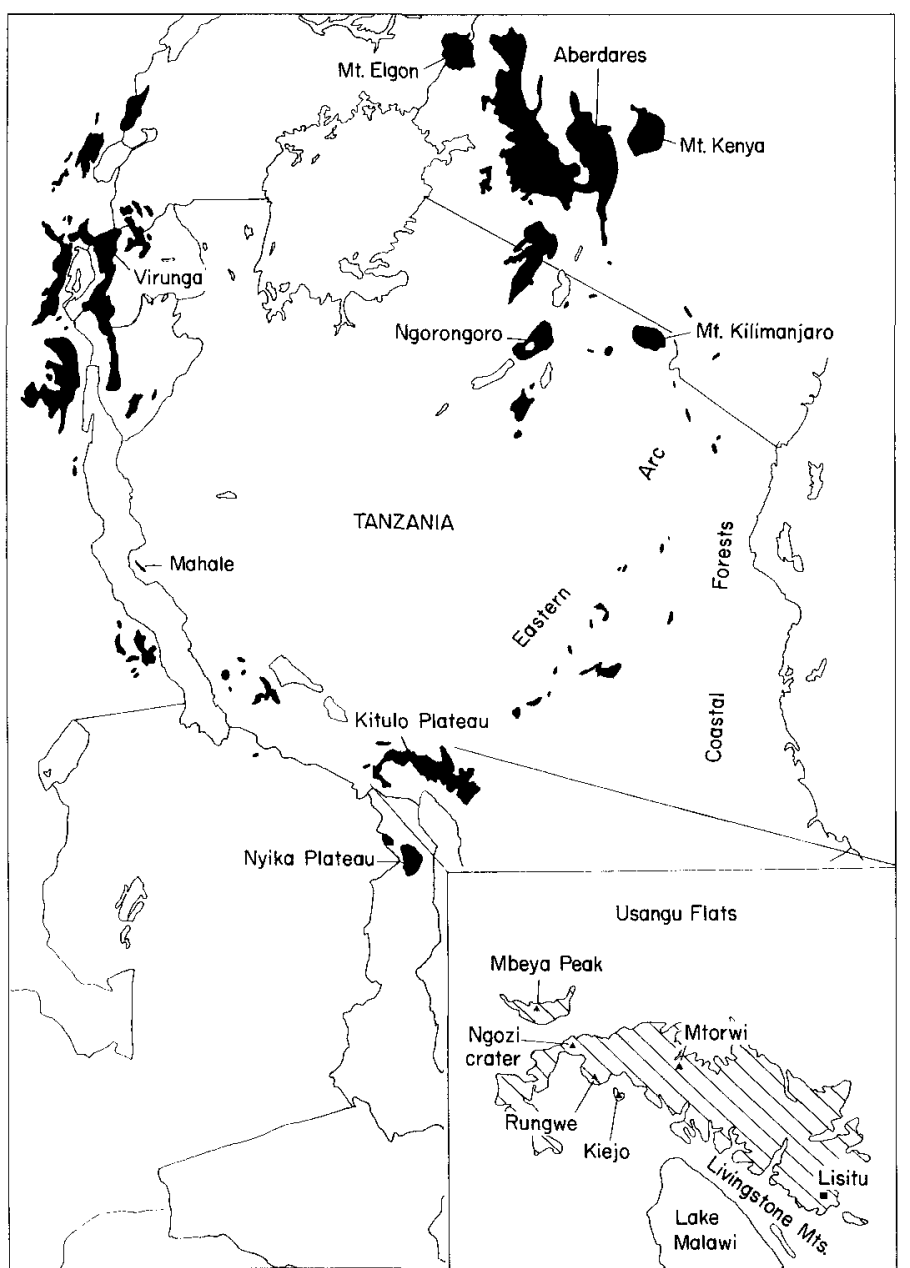

Figure 1. Location of Kitulo Plateau in eastern Africa, with areas higher than $2000 \mathrm{~m}$ marked in black.
Rungwe. Many of these areas have been affected by fires set by humans (Greenway, 1955; Pócs, 1976) and on Kilimanjaro by tourism (Newmark and Nguye, 1991; Harcourt and Stewart, 1993), but these activities are not reported to affect floristic diversity severely. Outside Tanzania, the area perhaps most similar to Kitulo Plateau is Nyika Plateau in northern Malawi, an area of similar size and partly protected as a national park. Other eastern African areas of upland grassland protected by national park status are: the Aberdares, Mt Kenya and Mt Elgon in Kenya; Bale Mountain in Ethiopia; and the Virunga Mountains in Rwanda and Zaire (IUCN/ UNEP, 1987).
The Kitulo Plateau is without any protective status, and in recent years has been increasingly cultivated for potatoes and pyrethrum, raising concern over the future of the flora. Unlike fire and tourism, or traditional cattlegrazing such as that observed by Gillman, cultivation has an immediate and long-term affect on indigenous vegetation because many of the plants are geophytes arising from underground bulbs or tubers, which are disturbed during digging. In addition to smallholder cultivation, a government farm was established in 1965, initially for sheep and cereals under the National Ranching Company (NARCO). In 1974, under the government-controlled Dairy Farming Company 
(DAFCO) the emphasis of the farm changed to dairy farming and this continues to the present day, with 18,500 ha of the 27,300 ha plateau held by the farm (TISCO, 1983; Lovett et al., in press).

This paper briefly describes the geography, climate, vegetation and conservation interest of the Kitulo; and presents data on changes in land use from 1973 to 1989 as estimated by digital analysis of satellite imagery, with the aim of highlighting the botanical importance of the area and the threats to it.

\section{Geography, climate and vegetation}

The Kitulo Plateau covers $273 \mathrm{sq} \mathrm{km}$ of rolling hills dissected by marshes and streams at an altitude above $2500 \mathrm{~m}$ in Makete District, Iringa Region $\left(8^{\circ} 58^{\prime}-9^{\circ} 10^{\prime} \mathrm{S}, 33^{\circ} 46^{\prime}-33^{\circ} 58^{\prime} \mathrm{E}\right)$ just north of the high-rainfall area around Lake Malawi (Figure 1). The south-western edge is the steep rift valley escarpment overlooking the volcanoes of Rungwe and Kiejo. To the north-east, the plateau is bounded by the crystalline gneissic ridge of the Kipengere Mountains, peaking at $2960 \mathrm{~m}$ on Mt Mtorwi, with gaps at Matamba and Ndumbi. The eastern edge of the plateau is marked by the change to the highly dissected valleys and ridges of the Livingstone and Kipengere Mountains. To the west, the plateau is connected to the Poroto Mountains by the ridge that divides the Lake Malawi valley from the Usangu plains and Rukwa rift.

The plateau is made up of Pliocene basaltic and phonolitic lavas up to $150 \mathrm{~m}$ in depth, overlying pre-Karoo formations (Harkin, 1960). The Kipengere ridge stopped the eastern flow of the lavas, except at the Matamba and Ndumbi gaps. Eruptions from Rungwe later covered the plateau with pumice. The soils are organic loams over pumice or schists and quartzites, with thickness depending on slope, exposure or waterlogging. The climate is dominated by the proximity of Lake Malawi, with heavy rain falling in convectional thunderstorms arising from the lake. Mean annual rainfall is about $1500 \mathrm{~mm}$, with a single rainy season from November to May,

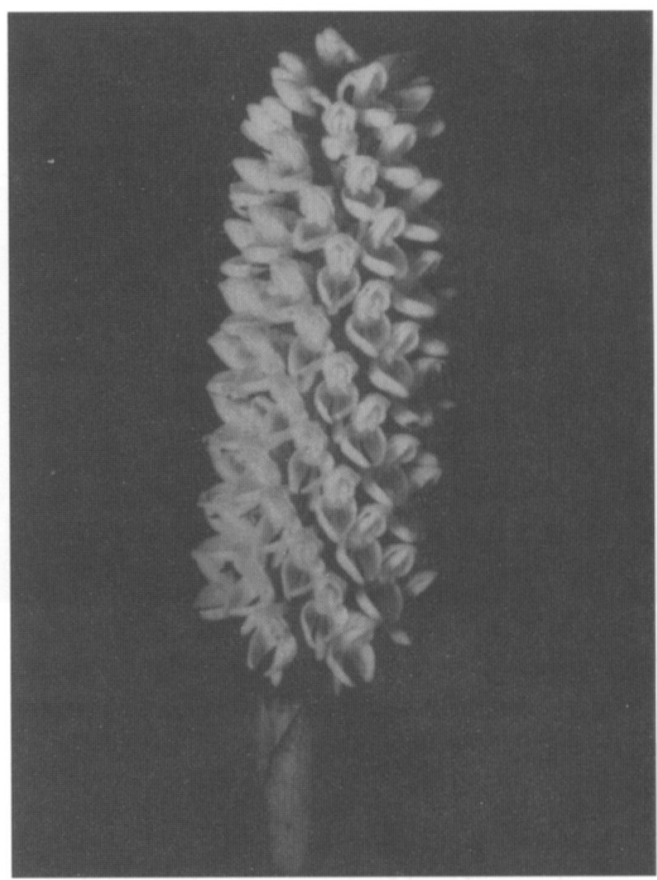

Disa fragrans, a Kitulo orchid (Jilly Lovett).

peaking in April. There is a marked dry season from May to October, with almost nightly frosts from June to August (TISCO, 1983). As part of the upper Great Ruaha River catchment, the plateau is an important water catchment area, with the Ndumbi River draining into the Usangu Flats

The vegetation of the plateau is relatively well known (Cribb and Leedal, 1982; Lovett et al., in press). The grassland can be divided into three main types: well-drained grasslands on volcanic soil, waterlogged bogs, and rocky ridges and associated talus slopes. Large areas are burnt every year during the dry season. Montane forest trees, for example Juniperus procera and Hagenia abyssinica, occasionally occur in stream valleys protected from fire. Forest species are found even in clefts of exposed rocky outcrops on ridge-tops at $2750 \mathrm{~m}$ on the slopes of Mtorwi. For example, stunted Rapanea melanophloeos and Clausena anisata were seen growing out of rock cracks and in crevices. Montane forest with bamboo thickets grow on the steep south-western slopes covered by the 26,365-ha Livingstone Forest Reserve, and in the Ndumbi gap, which is 


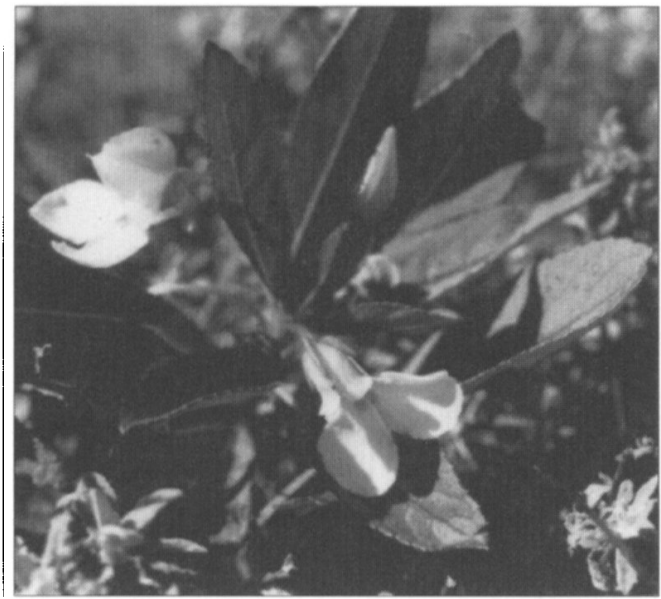

Impatiens rosulata, a Kitulo endemic (Jilly Lovett).

covered by the 2739-ha Ndumbi Valley Forest Reserve.

\section{Biological importance}

The Kitulo Plateau is a botanically important site for several reasons: it is relatively rich in species, there are a significant number of species of restricted distribution, and it is phytogeographically unusual. A preliminary check-list of the plateau records 350 plant taxa
(Lovett et al., in press). Although not high compared with other tropical areas, it is of similar magnitude to the 278 Afro-alpine taxa recorded from the highest East African mountains (Hedberg, 1957). Nearly 20 of the Kitulo plant taxa are of restricted distribution (Table 1). Three of these (Brachystelma kituloensis, Impatiens rosulata and Pterygodium ukingense) are known only from the plateau. The others are also found in nearby areas of upland grassland, for example on Lisitu Ridge in the Livingstone Mountains, Mbeya Peak, Nyika Plateau, and in the case of Moraea callista as far north as the Uluguru Mountains (Goldblatt, 1977).

Many of the plants, although very localized in their distribution, can be abundant on the plateau. For example, the iris-like Moraea tanzanica and $M$. callista flower in profusion in January and February. The red-hot poker Kniphofia kirkii, and giant lobelia Lobelia mildbraedii form dense stands in boggy valleys, and the balsam Impatiens rosulata is common all over the plateau. Additional rare species such as Impatiens leedalii occur in the nearby montane forests, which are otherwise composed mainly of widespread plants. The flora has pronounced southern African affinities and some of the endemics appear to be derived from southern African species. For

\begin{tabular}{ll}
\hline Species & Distribution \\
\hline Anagallis kingaensis & Kitulo, Rungwe \\
Brachystelma kituloensis & Kitulo \\
Clemetopsis villosa subsp. uhehensis & Kitulo, Rungwe, Udzungwa \\
Cyphia rupestris & Kitulo, Mbeya \\
Cyphia ubenensis & Kitulo, Livingstones \\
Digitaria myurus & Kitulo, Mbeya \\
Disa ukingensis & Kitulo, Nyika, Mbeya \\
Galium tanganyikense & Kitulo, Kipengere \\
Habenaria occlusa & Kitulo, Mbeya \\
Impatiens cribbii & Kitulo, Kipengere \\
Impatiens hydrogetonoides subsp. kituloensis & Kitulo, Kipengere \\
Impatiens rosulata & Kitulo \\
Kniphofia kirkii & Kitulo, Kipengere \\
Moraea callista & Kitulo, Kipengere, \\
& Uluguru, Livingstones \\
Moraea tanzanica & Kitulo, Rungwe, Mbeya, \\
& Livingstones, Nyika \\
Protea linearifolia & Kitulo, Njombe \\
Pterygodium ukingense & Kitulo \\
\hline
\end{tabular}

Table 1. Examples of endemic or near-endemic plant species found on the Kitulo Plateau (Lovett et al.; Goyder, 1990; Beard, 1992) 
Edge of grassland disturbed by rangeland management on Kitulo Dairy Farm (Jilly Lovett).

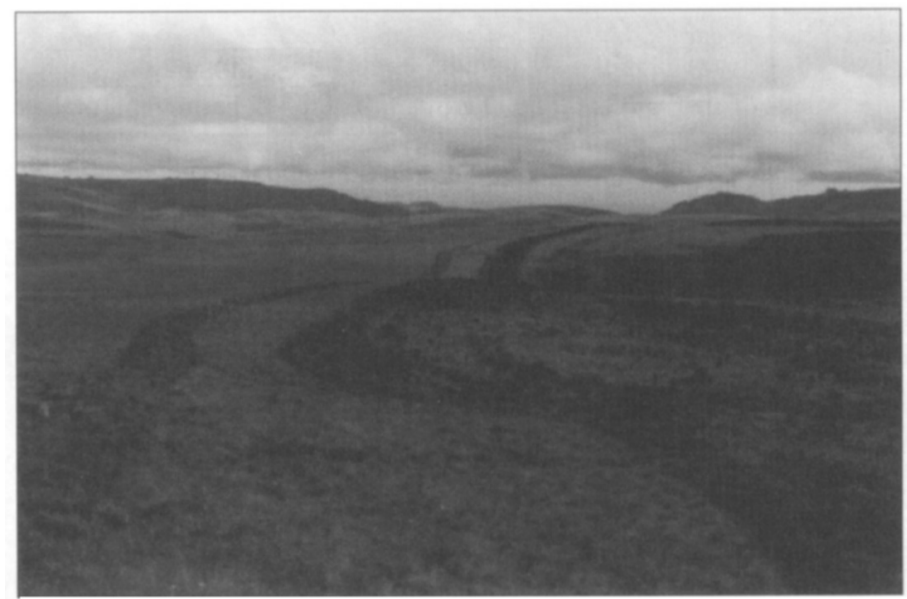

example the nearest relative to Brachystelma kituloensis is $B$. coddii from southern Africa (Goyder, 1990). The orchid Pterygodium ukingense is the only member of the genus outside southern Africa, and the prostrate sugar-bush Protea linearifolia belongs to a mainly southern African genus (Beard, 1992).

Although the plateau is most renowned for its flora, it is also a breeding area for the endangered Denham's bustard Neotis denhami (Anon, 1993). Interesting butterflies include the satyrid, Neocoenyra petersi, a Kitulo endemic (Kielland, 1990), which was recently rediscovered on the plateau after 41 years (T. C. E. Congdon, pers. comm.). Southern African affinities can be seen in the skipper Kedestes barberae, a south African butterfly with its most northerly record on the Kitulo (Kielland, 1990).

\section{Changes in land use}

The traditional land use described by Gillman in 1927 still exists today. People from villages around the Kitulo take turns to come up and live on the plateau to graze cattle herds. The climate is considered too cold to stay there permanently. However, there have been major changes in land use in recent years.

The planting of forestry trial plots on the plateau in the 1950s was the first change from traditional land use, but large-scale plan- tations were never established. Development of the area from 1965 to 1981 was reviewed in TISCO (1983). In 1965 the 20,000 ha NARCO farm was established, with funding from FAO/UNDP, to raise sheep, improve pasture and grow wheat. Cereal production was halted in 1968 because wheat did not grow well, and in 1973 the low price of wool and difficulties in marketing mutton resulted in phasing out of sheep and the introduction of beef and dairy cattle, with a loan from the World Bank. In 1974 the management of the farm was transferred from NARCO to DAFCO, which is responsible for dairy-farming operations in Tanzania. In 1978 a longterm development plan was initiated with expansion of dairy activities in 1980/81 with assistance from the World Food Programme. Much of the farm was left as natural grassland, but 10,737 ha were planted or oversown in 1978. The area of managed grassland was reduced to 6787 ha in 1983 .

The socio-economic situation in Makete District has been reviewed by Wardell (1991). In comparison with some other areas of Tanzania, population growth in Makete District has been comparatively low with the total population rising from 59,256 to 115,480 between 1957 and 1988, an annual growth rate of 0.4-1.0 per cent. This is due to out-migration of labour from this remote area, which also results in a skew in the male:female ratio, with 40 per cent more women than men. 


\begin{tabular}{|c|c|c|c|c|c|c|}
\hline \multirow{3}{*}{$\begin{array}{l}\text { Land } \\
\text { cover } \\
\text { type }\end{array}$} & \multicolumn{6}{|l|}{ Year } \\
\hline & \multicolumn{2}{|l|}{1973} & \multicolumn{2}{|l|}{$\underline{1981}$} & \multicolumn{2}{|l|}{1989} \\
\hline & Farm & Total & Farm & Total & Farm & Total \\
\hline 1 & 538 & 905 & 960 & 2123 & 431 & 544 \\
\hline 2 & 24 & 73 & 44 & 74 & 353 & 894 \\
\hline 3 & 245 & 874 & 70 & 216 & 531 & 1944 \\
\hline 4 & 83 & 110 & 938 & 1198 & 429 & 544 \\
\hline Total & 890 & 1962 & 2012 & 3861 & 1734 & 3926 \\
\hline
\end{tabular}

Disturbance classes: 1 , no or sparse vegetation; 2 , sparse vegetation cover; 3 , lightly disturbed grassland; 4 , active agricultural areas with standing crops.

Table 2. Area in hectares of disturbed grassland in 1973, 1981 and 1989 on Kitulo Plateau as measured by satellite imagery, divided into four different disturbance classes. In addition to the total area of disturbed grassland on the plateau, the area immediately around the Kitulo Dairy Farm headquarters is given.
Present livestock numbers in the district (about 30,000 cattle, sheep and goats) are considered to be within the carrying capacity of the land and not to have caused land degradation on a significant scale. There has, however, been increased use of land covered by natural forest and grassland for cultivation, which is attributed to the rising population and has caused conflicts between pastoralists and farmers. This conflict is reported to be exacerbated by local cultivators being prevented from using the area covered by the DAFCO farm (Wardell, 1991).

Recently there has been a marked increase in cultivation for potatoes and pyrethrum on the plateau. Extensive areas of new fields were observed being established in 1990 in the area between the Matamba Gap and the Ndumbi stream. In mid-1991 the Tanzanian Ministry for Agriculture and Livestock Development announced substantial increases in the producer price of pyrethrum in order to stimulate production, and it is thought that this will lead to big increases in the area cultivated on Kitulo (Wardell, 1991). However, in practice, marketing problems have discouraged farmers from planting pyrethrum, and the focus has been on potatoes.

\section{Estimation of disturbance using satellite remote-sensing}

Changes of land use can be monitored with images obtained by satellite remote-sensing. In this case, data from the Landsat satellite series, initially launched in 1972, were used. The satellites carry a multispectral scanner (MSS), which records light reflection from the earth's surface in four bands: two in visible light (channels 1 and 2) and two in near infrared (channels 3 and 4). The reflectance is stored digitally in the form of pixels, which correspond to an area of approximately $80 \times$ $80 \mathrm{~m}$ on the ground. Each pixel represents a measurement of the quality of light reflected from the ground in each of the four channels. Vegetation cover can be estimated because photosynthetic plants absorb light energy in the wavelengths measured by channel 2 , but reflect strongly in channel 4 . The difference between these two channels has been shown to be an accurate indicator of photosynthetic activity (Tucker, 1979). For example, the high photosynthetic activity of agricultural crops makes them readily distinguishable from natural grasslands. Burnt areas, being black, absorb light energy, and are easily differentiated because they have low reflectance in all channels. Disturbed ground with exposed soil or rock gives a particularly high reflectance in all channels.

Digital satellite image data from three Landsat MSS scenes covering Kitulo plateau were available at the Geographical Institute, Copenhagen: Row/Path 182/066 of 4 September 1973 and 27 June 1981; and Row/Path 169/066 of 17 September 1989. The images were corrected for atmospheric changes so that the spectral variation in each image was equivalent. Unfortunately, data after 1989 was not available to us, and so the 

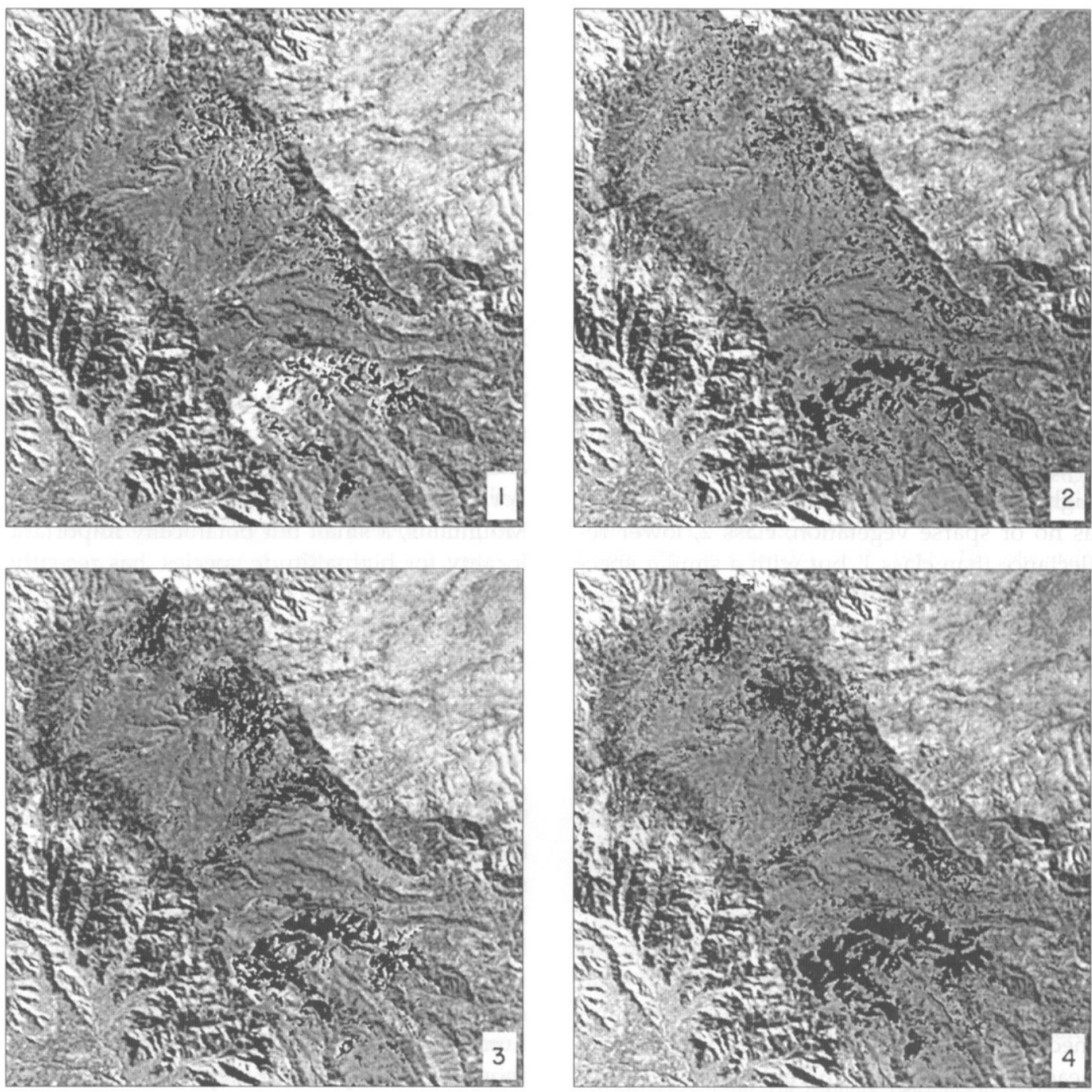

Figure 2. Change in land use on Kitulo Plateau as estimated by satellite remote-sensing. The areas in black are the total areas in disturbance classes 1,2,3, and 4. For clarity, the background image is the first principal component of the 1981 image, which was free of burnt areas and cloud. Each picture covers approximately 25 $\mathrm{km} \mathrm{sq.} 1,1973 ; 2,1981 ; 3,1989 ; 4$, total of all areas on the three images.

most recent changes in land use following increases in producer price of pyrethrum could not be assessed. Digital image data was analysed using the CHIPS satellite image processing system (Andersen et al., 1992). Resolution is $80 \times 80 \mathrm{~m}$, and the images have been geometrically registered to the UTM system and resampled with cubic convolution into $50 \times 50 \mathrm{~m}$ pixels. The images were coregistered with a residual error (root mean square) of under 0.8 of a pixel. The lava plateau of Kitulo is clearly visible on the images, contrasting markedly with the steepsided valleys and ridges of the adjacent Kipengere and Livingstone Mountains. The area of the plateau was measured as $273 \mathrm{sq} \mathrm{km}$.

Visual interpretation of the images clearly showed marked differences in reflectance both within and between the images, which could be correlated with known areas of disturbance 
and agricultural activity. A parallelepiped classification (Rasmussen, 1993) using different spectral levels from three channels $(1,2$ and 4) was made based on observed colour differences between the channels. Four types of spectral signatures were differentiated, which can be correlated to vegetation cover and disturbance using information obtained during visits to Kitulo Plateau between 1986 and 1992, and ground-truthing of other parts of the 1989 image. Cleared areas on the Kitulo Dairy Farm are easily interpreted on the image and statistics from these areas have been used to support the classification. Four types of disturbance were recognized: class 1 , high reflection in all channels was interpreted as no or sparse vegetation; class 2, lower reflectance than class 1 , but with a similar spectral pattern was interpreted as sparse vegetation cover; class 3 , higher reflectance in all channels compared with areas known to be undisturbed was interpreted as lightly disturbed grassland; class 4 , a significant difference between channel 2 and 4 was interpreted as active agricultural areas. Burnt areas were not classified as disturbance. A possible source of error is exposed ridges catching the sun giving high reflections and so being misclassified as bare ground.

The area of each class on the plateau for each of the three images, divided into total area for the plateau, and the area in the immediate vicinity of the Kitulo Dairy Farm headquarters, is given in Table 2. The disturbance was not necessarily in the same place on each image. There is an increase in the amount of disturbance observed in the images, from 1962 ha in 1973 to 3962 ha in 1989 , with the area around the dairy farm headquarters contributing between 43 per cent and 52 per cent of the total area. The spectral signatures interpreted as disturbance were not always in the same place on each image. When the total area in all four disturbance classes on the three images was compiled, 6411 ha, or 24 per cent of the plateau, were affected (Figure 2). One explanation of this is that areas that have been disturbed and subsequently left fallow recover the reflectance of natural grassland. For example, areas that are definitely part of the dairy farm field system in the 1981 image, do not register as disturbed in the 1989 image. If this is the case, then the actual area disturbed between 1973 and 1989 might be much greater than estimated here. More detailed studies are needed to resolve this.

\section{Conservation}

High-altitude heaths and grasslands in eastern Africa generally need to be considered as being of conservation importance because they tend to be relatively small habitat islands and so are vulnerable to changes in land use. For example, Lisitu Ridge in the Livingstone Mountains, a small but botanically important locality for high-altitude species, has recently been extensively damaged by extraction of materials for road building (Spurrier, 1993). However, their protection in areas of multiple land-use raises some complex issues.

The presence of many endemic or near endemic species suggests that a high-altitude grassland habitat has been present on Kitulo Plateau for a long time. Natural fires started by lightning strikes in the frequent thunderstorms over the plateau and the presence of large herbivores for millions of years would have resulted in the vegetation being adapted to burning and grazing. The plateau has almost certainly had a long history of use by humans, probably for thousands if not tens of thousands of years. Except for occasional bushbuck, there are no large wild herbivores present on the plateau today. The occurrence of montane forest trees in valleys and rock crevices indicates that in the absence of grazing and fire, montane forest would be more extensive on the plateau. The flora is thus for the most part maintained by traditional landuse and no real conflict is apparent between past low density traditional cattle herding and conservation of the flora, if stocking levels remain sufficiently low to avoid overgrazing and erosion. Maintaining high species diversity in an area of fluctuating climate may even be important in traditional land-use, because species-rich grasslands survive drought better than species-poor grassland, producing more 
biomass and recovering faster (Tilman and Downing, 1993). A similar situation of combining traditional land use with biological conservation exists in Europe; for example grazing is not seen as a threat to rare endemics in the Greek flora (Strid, 1989).

What effect have changes in land use over the last 20 years had on the flora? As the data presented here from satellite remote-sensing demonstrate, there has been a substantial increase in the area disturbed on the plateau, largely confined to the area around the dairy farm headquarters and the Ndumbi Valley. Many plateau plant species are perennial geophytes, flowering in the warm wet season and dying back in the cold dry season, so avoiding dry season fires. Digging up perennating organs can be expected to affect species composition, although in Greece perennial geophytes survive traditional tilling by being sufficiently deep-seated (Strid, 1989). During the course of preparing a botanical check-list of the area (Lovett et al., in press), it was clear that grassland is replaced by a shrubby sward following disturbance. However, agricultural projects on the Kitulo are thought to have had little direct effect on the scattered populations of Lobelia mildbraedii (Knox, 1993), although there is no long-term data to support this assumption. In the absence of ecological monitoring to determine the effects of the substantial land-use changes taking place, there is a strong case for the establishment of a nature reserve to conserve the Kitulo flora. The protective value of the reserve could be combined with traditional land use for cattle grazing, and would also serve to prevent soil erosion and maintain catchment values.

\section{Acknowledgments}

We gratefully acknowledge permission from the Tanzania Commission for Science and Technology to conduct research in Tanzania. Funding for fieldwork for J. L. was provided by the National Geographical Society and Missouri Botanical Garden. The satellite images and field-work costs for E. P. were provided through the Agricultural and Ecological Consequences of Deforestation and Afforestation in Tanzania and Zambia based on Satellite Remote Sensing funded by DANIDA through the ENRECA programme. We are very grateful for comments on an earlier draft of the manuscript from Colin Congdon, Sally Bidgood, Dr Alan Rodgers, Richard Minja, Dr Phillip Cribb and two anonymous referees.

\section{References}

Andersen, H.S., Grundtmann, J., Rasmussen, K. and Fog, B. 1992. CHIPS version 3.0. User's Guide. Institute of Geography, University of Copenhagen.

Anon. 1993. Fears for upland grassland. Miombo, 10, 9.

Beard, J.S. 1992. The Proteas of Tropical Africa. Kangaroo Press, Hong Kong.

Brenan, J.P.M. 1978. Some aspects of the phytogeography of tropical Africa. Annals of the Missouri Botanical Garden, 65, 437-478.

Cribb, P.J. and Leedal, G.P. 1982. The Mountain Flowers of Southern Tanzania. A. A. Balkema, Rotterdam.

Elton, J.F. and Cotteril, H.B. 1879. Travels and Researches among the Lakes and Mountains of Eastern and Central Africa. London.

Gillman, C. 1927. South-West Tanganyika Territory. The Geographical Journal, 69, 96-131.

Goldblatt, P. 1977. Systematics of Moraea (Iridaceae) in tropical Africa. Annals of the Missouri Botanical Garden, 64, 243-295.

Goyder, D.J. 1990. A new species of Brachystelma (Asclepiadaceae) from southern Tanzania. Kew Bulletin, 45, 729-731.

Greenway, P.J. 1955. Ecological observations on an extinct East African volcanic mountain. Journal of Ecology, 43, 544-563.

Harcourt, A. and Stewart, K. 1993. Kilimanjaro: African treasure or rubbish tip? Miombo, 10, 1.

Harkin, D.A. 1960. The Rungwe Volcanics at the northern end of Lake Nyasa. Geological Survey of Tanganyika Memoir II. Dar es Salaam: Government Printer.

Hedberg, O. 1957. Afroalpine vascular plants. A taxonomic revision. Symbolae Botanicae Upsalienses, 15, 1-411.

Hoyle, B.S. 1986. Gillman of Tanganyika, 1882-1946: Pioneer Geographer. The Geographical Journal, 152, 354-366.

IUCN/UNEP. 1987. The IUCN Directory of Afrotropical Protected Areas. IUCN, Gland, Switzerland and Cambridge, UK.

Kielland, J. 1990. Butterflies of Tanzania. Hill House, Melbourne and London.

Knox, E. B. 1993. The conservation status of the giant senecios and giant lobelias in Eastern Africa. Opera Botanica, 121, 195-216. 
Lovett, J.C. 1990. The Kitulo Plateau. Swara, 13, $10-11$.

Lovett, J.C. 1992. Main report of the Udzungwa Forest Management Project Identification Mission. Ministry of Foreign Affairs, Copenhagen. 108 pp. plus 16 technical annexes.

Lovett, J.C. 1993. Temperate and tropical floras in Tanzania. Opera Botanica, 121, 217-227.

Lovett, J.C., Gereau, R.E. and Sidwell, K.J. In press. Vegetation and phytogeography of the Kitulo Plateau, southern Tanzania. Proceedings of the XIIth AETFAT Congress, Zomba, Malawi.

Newmark, W.D. and Nguye, P.A. 1991. Recreational impacts of tourism along the Marangu route in Kilimanjaro National Park. In The Conservation of Mount Kilimanjaro (ed. W. D. Newmark), pp. 47-51. IUCN, Gland, Switzerland and Cambridge.

Pócs, T. 1976. Vegetation mapping in the Uluguru mountains (Tanzania, East Africa). Boissiera, 24, 477-498.

Polhill, R.M. 1968. Tanzania. Acta Phytogeographica Suecica, 54, 166-178.

Polhill, R.M. 1988. East Africa (Kenya, Tanzania, Uganda). In Floristic Inventory of Tropical Countries (eds D. G. Campbell and D. Hammond), pp. 218-231. New York Botanical Garden, New York.

Rasmussen, K. 1993. Introduction to Satellite Remote Sensing. Institute of Geography, University of Copenhagen.

Rodgers, W.A. 1993. The conservation of the forest resources of eastern Africa: past influences, present practices and future needs. In Biogeography and Ecology of the Rain Forests of Eastern Africa (eds J. C. Lovett and S. K. Wasser), pp. 283-331. Cambridge University Press, Cambridge.
Sheil, D. 1992. Tanzanian coastal forests - unique, threatened, and overlooked. Oryx, 26, 107-114.

Spurrier, M. 1993. Destruction of habitat on Lisitu Ridge, south-western Tanzania. Miombo, 10, 8.

Strid, A. 1989. Endemism and speciation in the Greek flora. In The Davis and Hedge Festschrift (ed. K. Tan), pp. 27-44. Edinburgh University Press.

Tilman, D. and Downing, J.A. 1993. Biodiversity and stability in grasslands. Nature, 367, 363-365.

TISCO. 1983. Dairy Development for Kitulo Plateau: A feasibility study for Tanzania livestock development authority, Dar es Salaam. Tanzania Industrial Studies and Consulting Organisation, Dar es Salaam, Tanzania.

Tucker, C.J. 1979. Red and photographic infrared linear combinations for monitoring vegetation. Remote Sensing and Environment, 15, 255-261.

Wardell, D.A. 1991. Makete District Forest Conseroation and Land-use Management Project. Identification report and preliminary project proposals for Makete District. DANIDA, Dar es Salaam.

White, F. 1983. The Vegetation of Africa. UNESCO, Paris.

Jon C. Lovett, Botanical Museum, University of Copenhagen, Gothersgade 130, DK-1123, Copenhagen, Denmark and Department of Botany, University of Dar es Salaam, PO Box 35060, Dar es Salaam, Tanzania.

Erik Prins, Institute of Geography, University of Copenhagen, Ostervoldgade 10, DK-1350, Copenhagen, Denmark. Present address: Ornis Consult, Vesterbrogade 140, DK-1620 Copenhagen, Denmark. 